Laboratorio de Arte, 7-1994 http://dx.doi.org/10.12795/LA.1994.i07.18

\title{
NOTICIAS INÉDITAS DEL ENTALLADOR SEVILLANO CRISÓSTOMO ANTÚNEZ *
}

\author{
POR Bentto Navarrete Prieto
}

La personalidad del entallador o escultor -como a veces se denominaCrisóstomo Antúnez permanecía hasta la fecha desconocida. De él solo se tenían tres noticias; La primera y más antigüa data del año 1587 cuando aparece como testigo en la escritura de dote del escultor Juan Martínez Montañés, que contraía matrimonio con Ana de Villegas, hija del ensamblador Juan Izquierdo '.

La segunda noticia nos lo vincula con Luis de Figueroa al realizar con él un retablo para el altar mayor de la iglesia del monasterio del Espíritu Santo ${ }^{2}$, obra afortunadamente conservada, ya que fue trasladada con anterioridad a 1780 a la parroquia de la Concepción de Brenes y constituía hasta ahora el único testimonio de su labor. En este retablo se nos presenta estilísticamente como seguidor de los modelos retablísticos de Alonso Matías en la casa profesa de los Jesuitas de Sevilla y presenta ya los modelos del retablo Barroco ${ }^{3}$.

La tercera noticia nos lo sitúa en 1626 como fiador en asunto relacionado con el retablo de la Concepción de San Gil ${ }^{4}$.

Pero en 1588, según documento encontrado en el Archivo de Protocolos Notariales de Sevilla (A.N.P.S.) ${ }^{5}$ dice haber recibido de Tomás Gómez clérigo presbitero Mayordomo del monasterio y convento de San Clemente de la ciudad de Sevilla en nombre de la Abadesa del monasterio Doña Constanza de Guzmán de Ribera, ochenta ducados por la hechura de la talla de las puertas del comulgatorio de la iglesia nueva- cuya consagración, tras las obras realizadas, sabemos que se llevó a cabo el 30 de Septiembre de 1588- y por sesenta paneles de talla que hizo para el púlpito de dicha iglesia, así mismo por lo que se le debía del antepecho del coro alto de dicha iglesia.. En el documento aparece como fedatario el

*. Queremos agradecer al Dr. Enrique Valdivieso y al Dr. Emilio Gómez Piñol la lectura y corrección de éste artículo, así como al Dr. Palomero Paramo la ayuda prestada durante la realización del mismo.

1. López Martínez, Celestino; Desde Martínez Montañés hasta Pedro Roldán, Sevilla, 1932, p. 227.

2. Ibídem, p. 49.

3. Palomero Páramo, Jesús M. El retablo sevillano del Renacimiento, Sevilla, 1983, p. 486-487.

4. A.A.V.V.; Documentos para la historia del arte de Andalucia, T. VIII, p. 79.

5. A.N.P.S. Legajo 177, Ecribano, Diego de la Barrera Farfán, oficio 1, 1588, folio 1146 r y v. 
pintor de imaginería Vasco Pereira, que sabemos intervino en la decoración mural de la iglesia ${ }^{6}$ y que éste documento nos lo confirma de nuevo, ya que, era normal que artistas que trabajaban para un mismo comitente se encargaran de dar fe de trabajos de sus compañeros.

La intervención de Vasco Pereira en San Clemente consistió en pintar las armas de Doña María de Portugal, viuda de Alfonso XI, sobre su tumba,y, en las pechinas de la bóveda del presbiterio, los evangelistas. Estas obras que se daban por perdidas han sido descubiertas tras la restauración llevada a cabo por Fernando Villanueva ${ }^{7}$ y concretamente el escudo de armas ha sido hallado sobre la tumba de Doña María de Portugal, además, han sido encontradas tras el retablo de la Virgen de la Antigüa un grupo de Profetas en grisalla presididos por la Virgen, obras ambas del pincel de Vasco Pereira.

De lo mencionado en el contrato de Antúnez se conservan las puertas del comulgatorio del lado del evangelio y el antepecho del coro alto, obras, que nos hacen ver en Crisóstomo Antúnez a un escultor de formación manierista siguiendo las pautas que en Sevilla marcaría el escultor abulense Juan Bautista Vázquez el Viejo. Posteriormente, y el retablo de Brenes es una buena prueba de ello, evolucionaría en formas más acordes con los modos del Barroco inicial.

Analizando la obra que el artista realiza en 1588 para San Clemente, podemos decir que las puertas son un ejemplo más de otras que se hicieron en la época, tanto para comulgatorios como para Sagrarios reservorios ${ }^{8}$.

A juzgar por el texto del documento las puertas en un principio eran las dos que se corresponden al lado de la epístola y el evangelio, pero lo cierto es que solo se conservan las del evangelio, ya que, las de la epístola actuales fueron realizadas entre 1713 y 1719 , en estilo bien distinto.

Las puertas del entallador Crisóstomo Antúnez, presentan cuatro registros principales, dos por cada hoja de la puerta, en las que se inscriben cabezas de querubines y elementos vegetales a modo de roleos.

Los cuatro Padres de la iglesia; San Gregorio, San Jerónimo, San Agustín y San Ambrosio aparecen representados con sus atributos iconográficos correspondientes y con ropajes amplios y ricos en plegados. Reposan sobre una peana similar a la utilizada por Jerónimo Hernández para otras puertas de un Sagrario

6. López Martínez, Celestino. Desde Martínez Montañés... Opus Cit., p. 198. Este documento aparece citado y relacionado en el conjunto de la obra del pintor en ; Serrera Contreras, Juan M. "Vasco Pereira, un pintor portugués en la Sevilla del último tercio del siglo XVI" en Archivo Hispalense, n. 213, 1987, p. 197-243

7. Villanueva, Fernando y Fernández, Rufina. Un proyecto de rehabilitación; El Real Monasterio de San Clemente, informe , Comisaría de la ciudad para 1992, Sevilla, 1991, p. 78-79-82.

Las pinturas de Vasco Pereira aparecen reproducidas en ésta obra, si bien no habían sido puestas en relación con la obra del pintor, considerándolas como obras manieristas de fines del XVI.

8. De los Rios Martínez, Esperanza. "Jerónimo Hernández y Antonio de Arfián: sus intervenciones en el primitivo retablo mayor de la parroquia de San Miguel de Jerez de la Frontera" en Atrio, n. 3, Sevilla, 1991, pp. 33-39. 
en Marchena en $1577^{9}$ y similar a otras realizadas para el Sagrario reservorio de la iglesia de San Miguel de Jerez de la Frontera ${ }^{10}$.

La policromía que presentan parece no ser la original, acusándose en el fondo de los registros repintes.

Su estilo nos hace ver en Antúnez a un representante de lo que Martín González llama "Manierismo expresivo" ". Por un lado vemos en la figura de San Jerónimo un manierismo movido, inestable, artifioso. El santo se debate en un movimiento berruguetesco, que hace que todo el cuerpo se llene de nerviosos plegados. Pero este manierismo por distorsión que lo que quiere es inscribir a la figura en el marco se acompaña de una falta de energía, quedando todo en un puro alarde ${ }^{12}$. La herencia castellana en su doble vertiente Juni y Berruguete están patentes. No es necesario recordar que estas formas serían traidas a Sevilla por Juan Bautista Vázquez el Viejo artista que sin duda alguna encuentra reflejo en la obra de Antúnez.

La otra faceta del manierismo, la de la sensación de masa y ausencia de profundidad, la del estatismo encuentra también reflejo en la obra de Antúnez. Si observamos los otros tres Padres de la iglesia, sus ropajes amplios y envolventes así como sus rostros ampulosos y carnosos recuerdan nuevamente las formas de Vázquez el Viejo.

La siguiente obra conservada y documentada, que permanecía inédita ya que nunca se había hecho mención de ella es el antepecho del coro alto.

En ella Antúnez se nos presenta como artista que sigue fielmente la tratadística del momento, observando su traza enteramente clásica. Consta de una gran celosía con motivos decorativos estrellados en la que se adosan ocho pilastras con capiteles corintios. Sobre ellas se eleva el entablamento. El friso presenta motivos de grutescos que resultan ser estilización severizada de un grabado del arquitecto e imaginero Francesco Ricciarelli ${ }^{13}$ que trabajó de 1556 a 1596. Decoración similar presentan las pilastras y semejante ornamento muestran las citadas puertas del Sagrario realizadas por Jerónimo Hernández en Marchena.

Sobre el friso se eleva la cornisa que presenta por cada pilastra un remate con un jarrón serliano. Este antepecho se levanta sobre unas ménsulas que compartimentan espacios donde, entre guirnaldas, se siúan atributos pasionarios. Todo el conjunto queda presidido por un principio eurítmico donde la simetría, proporción y armonía son patentes a la hora de repartirse los elementos decorativos.

Estilísticamente el antepecho se sitúa en la etapa renacentista en que la depuración decorativa comienza a realizarse y ello es patente en los motivos.

Con respecto al otro elemento que el contrato refería, los paneles del púlpito, no se conserva nada ya que el actual es obra realizada en hierro.

9. Morales, Alfredo y Serrera, Juan M. "Aportaciones a la obra de Jerónimo Hernández" en Archivo Español de Arte, T. LIV, 1981, p. 405-426.

10. De los Rios Martínez, Esperanza. "Jerónimo Hernández y Antonio de Arfián..." Opus Cit. p. 33-39

11. Martín González, J.J. "El manierismo en la escultura española" en Revista de Ideas Estéticas, n. 72 p. $302-312,1960$

12. Caturla, María Luisa. Arte de épocas inciertas, Madrid, 1944.

13. Berliner, Rudolf. Modelos ornamentales de los siglos XV al XVIII, Madrid, 1928, lámina 208. 

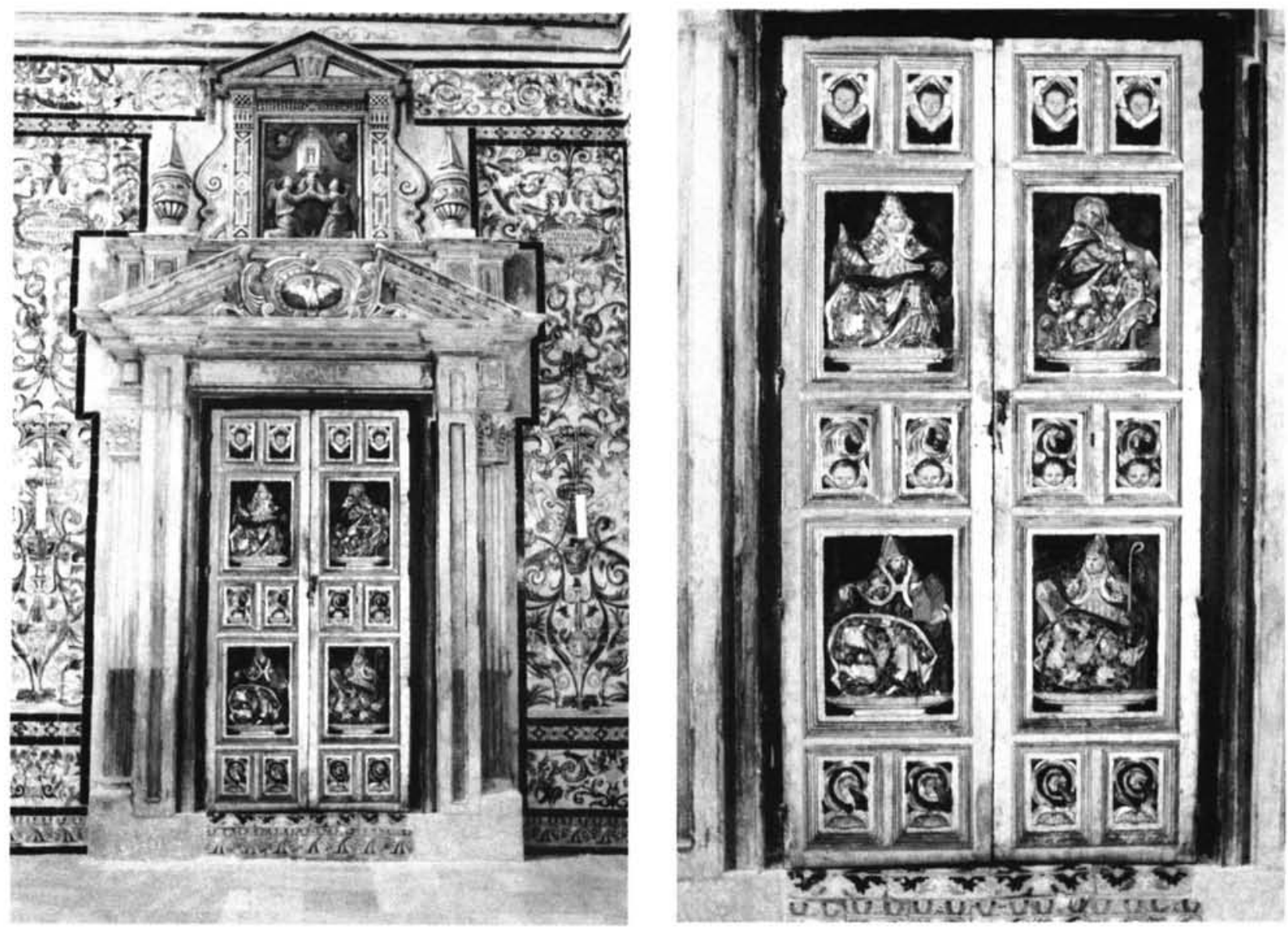

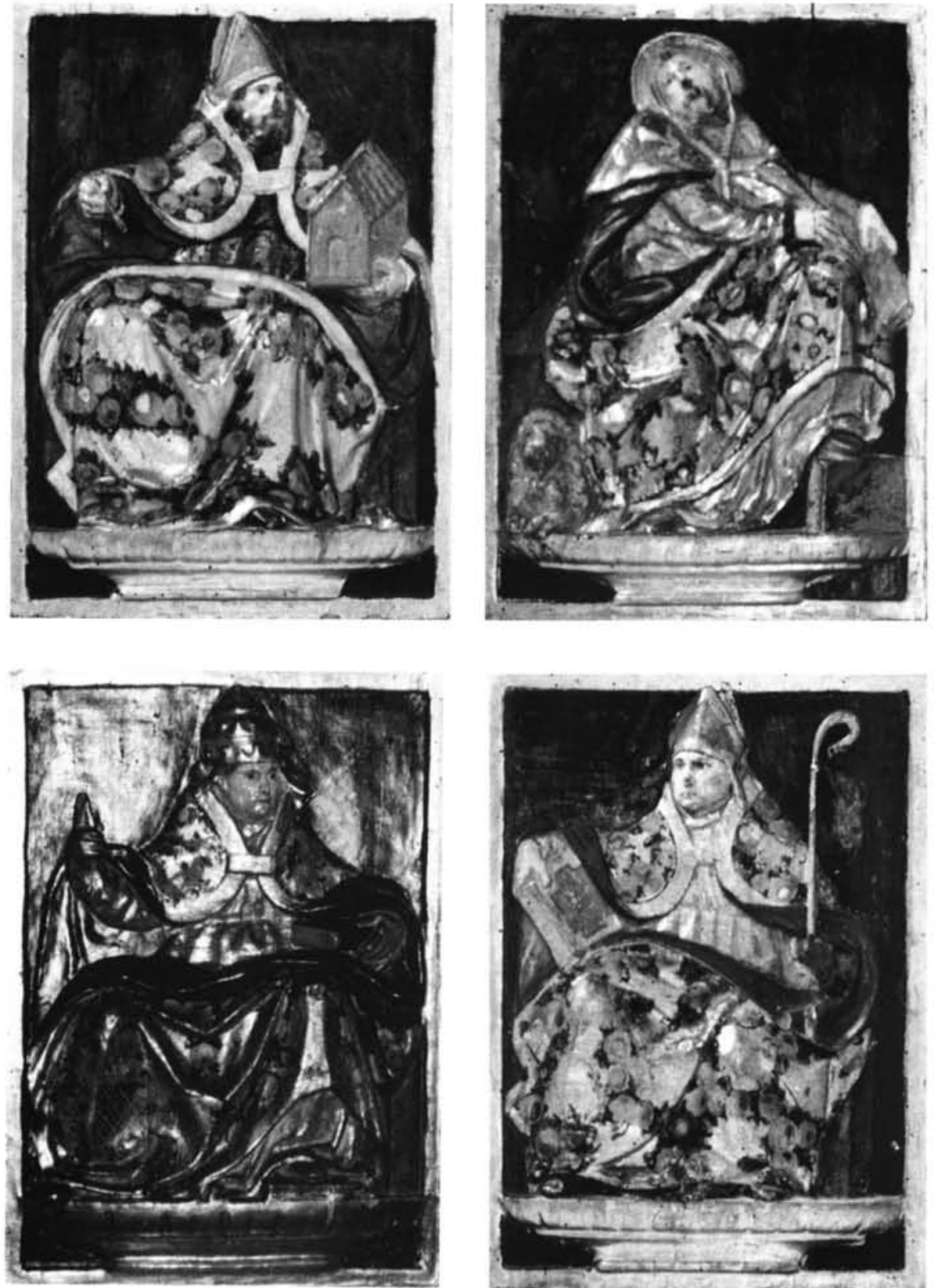

Lámina 2: Crisóstomo Antúnez: Puertas del Comulgatorio. Monasterio de San Clemente, Sevilla. Detalle de San Agustín, San Jerónimo, San Gregorio y San Ambrosio. 1588. 

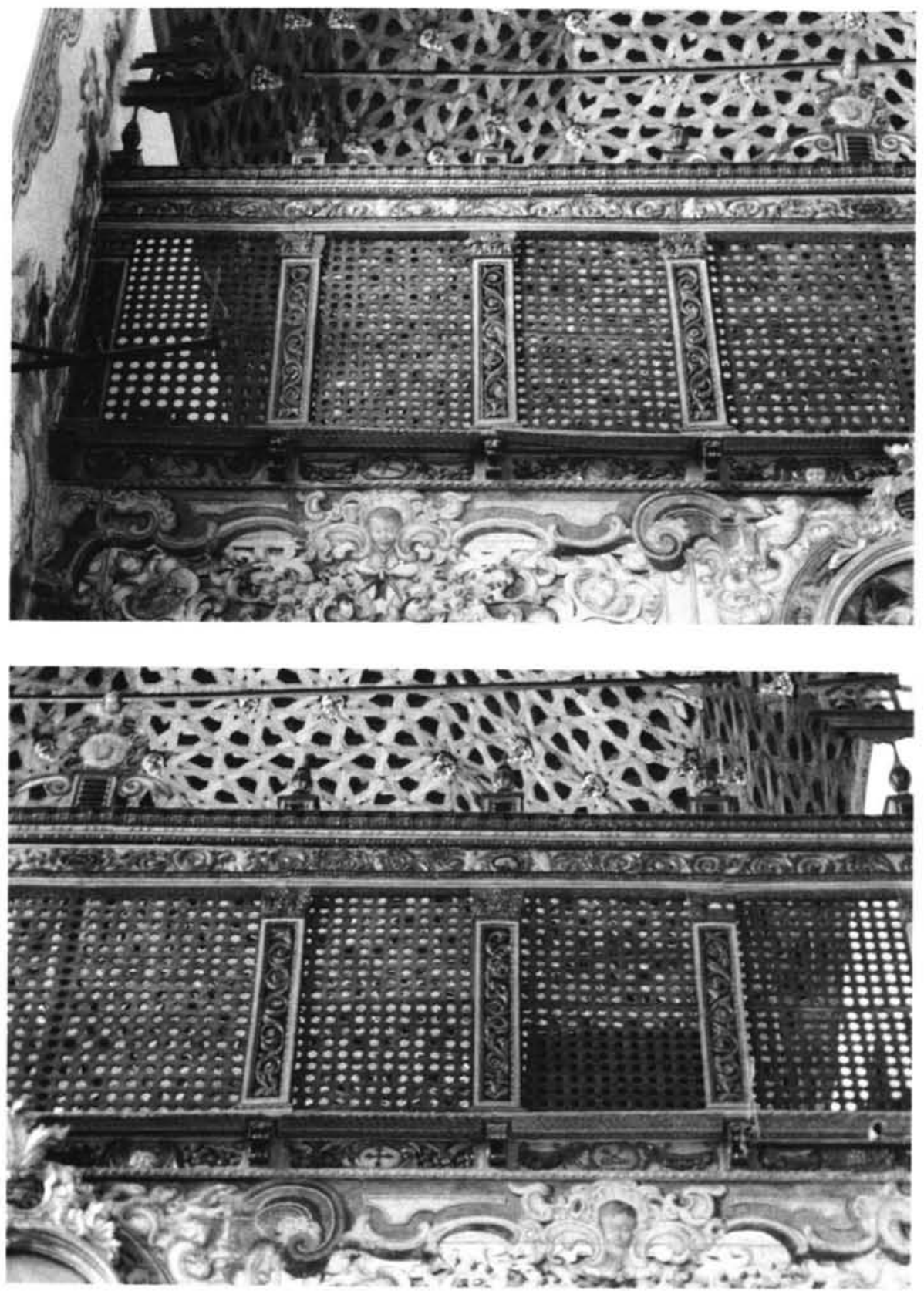

Lámina 3: Crisóstomo Antúnez: Antepecho del coro alto. Monasterio de San Clemente, Sevilla. 1588. 